\title{
Do Larger Churches Tolerate Pastoral Narcissism More Than Smaller Churches?
}

\author{
David R. Dunaetz, Hannah L. Jung, and Stephen S. Lambert \\ Azusa Pacific University
}

\begin{abstract}
Pastoral narcissism in churches is a problem, from both a theological and practical perspective. In this study, we explore the question of whether church size is related to tolerance for narcissism. In the popular press, pastors of megachurches are often portrayed as narcissistic. The Dominance Complementarity Model of narcissistic leaders (Grijalva \& Harms, 2004) predicts that churches which have less dominant followers, as may be the case in larger churches, would be more tolerant of narcissistic pastors than smaller churches. Yet larger churches also have the resources to hire the most qualified staff which would presumably exclude candidates high in narcissism. This quantitative study of 64 Christians who attend various evangelical churches in the United States examines how these two tendencies play out. The results indicate that Christians in larger churches tolerate narcissism significantly more than Christians in smaller churches. To prevent this phenomenon from having damaging effects on churches, larger churches need to be careful in their hiring practices by looking for signs of narcissism and to hold their leadership accountable for godly behavior.
\end{abstract}

Pastoral narcissism has been a source of concern since New Testament times. "Diotrephes, who loves be first" (3 John 9) and other Christian leaders like him have been causing distress to other Christians throughout the history of the church. Narcissism in pastors continues to be a concern (Meloy, 1986; Zondag, 2004) and perhaps a greater danger than ever due to the increasing narcissism in western culture in general (Twenge \& Campbell, 2009; Twenge, Konrath, Foster, Campbell, \& Bushman, 2008). This problem is perhaps even more common in megachurches which often have celebrity-like pastors with charismatic personalities (Dyer, 2012). Although most pastors are not especially high in narcissism (Patrick, 1990), those that are often wreak havoc in the church, especially among the staff members who work most closely with them (Patrick, 2010).

The purpose of this article is to present an overview of what we know about narcissistic leadership based on empirical studies and to answer the question whether Christians in larger churches tolerate pastoral narcissism more than Christians in smaller churches. This information will permit church leaders to prepare for, deal with, and perhaps even prevent some of the difficulties associated with narcissistic pastors.

\section{Definition of Narcissism}

The primary characteristic of narcissism is grandiosity, the belief in one's own importance and superiority. Narcissism can be defined as a personality trait that is characterized by arrogance, self-absorption, entitlement, and hostility (Rosenthal \& Pittinsky, 2006). As a personality trait, it describes a person's habitual thoughts, feelings, and behaviors. The strength of this personality trait is normally distributed as a bell curve; a few people are very low in narcissism (or high in humility), a few are very high in narcissism (narcissists), but most people are in the middle range. People high in narcissism are especially motivated by the need for power, status, and admiration; as leaders, they have little concern for their organizations apart from what responds to their own needs and little empathy for people with whom they work (Brunell et al., 2008; Rosenthal \& Pittinsky, 2006). The trait of narcissism should not be confused with the clinical diagnosis of narcissistic personality disorder (American Psychiatric Association, 2013). Such a diagnosis can only be 
made by a licensed mental health provider and must include both high narcissism (the personality trait) and distress or impairment because of the presence of this trait. Most narcissists do not experience distress or impairment because of their own thoughts and behavior.

In church contexts, working with a narcissistic leader becomes very complex because narcissism is strongly associated with lying and damaged interpersonal relationships (Lee \& Ashton, 2005). Keith Campbell of the University of Georgia and colleagues (2011) have proposed a three component model of narcissism-related phenomena in organizations to help people understand what happens in organizations with a narcissistic leader. First is the narcissistic leader's sense of self; the narcissistic self is characterized by specialness, vanity, a sense of entitlement, and a desire for power and esteem. To protect the narcissistic self and maintain positive self-esteem, the narcissist uses narcissistic self-regulatory strategies. These include seeking attention and admiration, bragging, taking credit for others' work, villainizing others, and manipulating coworkers, all of which enable the narcissist to maintain his ${ }^{1}$ positive self-view. When these strategies are successful, narcissists maintain or boost their already high self-esteem and are generally satisfied with the situations and contexts in which they find themselves. When these strategies are not successful, narcissists typically respond with anger and aggression. To succeed in these self-regulatory strategies, narcissists develop narcissistic relationships which are characterized by energy and enthusiasm, but by little or no empathy and low intimacy; they are often exploitative and manipulative to fit the narcissist's goals. These relationships may be painful and distressing for the person interacting with the narcissistic leader, sometimes leading to significant impairment in normal day-to-day life.

\section{Characteristics of Narcissistic Leaders}

From a biblical perspective, narcissism is among the most deadly of sins. "God opposes the proud, but gives grace to the humble" (James 4:6, ESV). "Everyone who exalts himself will be humbled, and he who humbles himself will be

\footnotetext{
${ }^{1}$ Because narcissism is especially prevalent among males, in contrast to females (Grijalva et al., 2015), and male pastors far outnumber female pastors in evangelical churches, masculine pronouns will be used to refer to narcissistic leaders in this paper. However, most of the phenomena would be likely to be true for narcissistic female leaders as well.
}

exalted" (Luke 14:11, ESV). For the Christian leader, narcissism is especially dangerous because it is

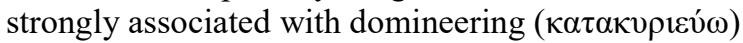
or lording it over, as it is sometimes translated. "Shepherd the flock of God . . . not domineering over those in your charge, but being examples to the flock" (I Peter 5:2-3, ESV). The personality trait of narcissism is one of the best predictors of dominating behavior (Brown \& Zeigler-Hill, 2004; Raskin, Novacek, \& Hogan, 1991) which is unacceptable for Christian leaders, "You know that those who are considered rulers of the Gentiles lord it over them . . . It shall not be so among you. But whoever would be great among you must be your servant, and whoever would be first among you must be slave of all" (Mark 10:42-44, NEV).

Narcissism in leaders has been empirically demonstrated to be associated with a number of characteristics and traits which are detrimental to the groups and organizations that they lead (Campbell, et al., 2011; Higgs, 2009; Maccoby, 2000): Narcissists tend to express more anger and aggression when receiving negative information than non-narcissists; this discourages subordinates from voicing concerns and providing accurate information about the state of the organization. Narcissists feel little need for selfimprovement; this limits personal growth in areas that would make them more effective as leaders. They are overconfident in their decisions, resulting in poor, costly decisions because the risks were not accurately weighed (Campbell, Goodie, \& Foster, 2004). They overstate their knowledge, falsely claiming they have knowledge of a subject in order to self-enhance; for example, narcissists, when asked who founded "Anglestan" (an non-existent, imaginary country), respond with greater certainty of knowing the answer than non-narcissists (Paulhus, Harms, Bruce, \& Lysy, 2003). They are less willing to make sacrifices for others and are less committed to the well-being of others, but they are more willing to exploit others (Campbell, Brunell, \& Finkel, 2006). They are more willing to engage in sexual relationships outside of marriage (Foster, Shrira, \& Campbell, 2006) and to coerce others into sexual relationships (Bushman, Bonacci, Van Dijk, \& Baumeister, 2003). Narcissism is associated with unethical behavior not only among the general population, but also specifically among pastors (Cooper, Pullig, \& Dickens, 2016).

Nevertheless, people are attracted to narcissists and often desire to be led by them. The Chocolate Cake Model of narcissistic leadership (Campbell, et al., 2011) predicts that a narcissistic leader is at first very attractive (a delicious choice) but eventually becomes repulsive and nauseating to those under his leadership. This model has been 
empirically verified (Ong, Roberts, Arthur, Woodman, \& Akehurst, 2016). Narcissists typically possess many of the qualities that predict leadership emergence (Brunell, et al., 2008; Higgs, 2009; Judge, LePine, \& Rich, 2006; Rosenthal \& Pittinsky, 2006). They are often extraverted, socially skilled, and charming. They express confidence and willingness to take control of situations. They perform well in front of large audiences, especially under pressure. They are attracted to power and are confident in their abilities to lead when others have failed. Because of these qualities, candidates high in narcissism are often preferred over other candidates for leadership positions.

But like a diet composed of only chocolate cake, the attractiveness of narcissistic leaders fades away and can lead to nausea and repulsion (Maccoby, 2000; Ong, et al., 2016). Their overconfidence leads to poor decision making. Their lack of empathy damages relationships. They are more concerned about indoctrinating others with their vision than learning about the situation from those on the ground. They shun criticism and publically humiliate those who question them or who provide information that they do not want to hear. Higgs (2009) argues that narcissistic leaders perfectly fit the paradigm of bad leadership. They abuse their power for personal gain, to enhance their reputation, and to hide their weaknesses rather than to serve others. They hurt others by bullying them through psychological abuse and by making subordinates feel incompetent, blaming them for the failures that they may experience. They exert power for their own personal self-esteem needs, often micromanaging or limiting a subordinate's initiative in order to demonstrate their own superiority. They achieve their goals through lying and other unethical, even illegal, behaviors, often responding to accusations with even more serious accusations against the accusers.

\section{Pastoral Narcissism and Church Size}

In the popular press, pastors of megachurches are often portrayed as being high in narcissism (Dyer, 2012; Patrick, 2010). If this is true, it may have disastrous consequences for a megachurch as the focus gradually shifts from glorifying the Lord to glorifying the pastor. In less severe cases, because narcissistic leaders tend to be aware of their limited empathy and ability to develop relationships (Campbell, Rudich, \& Sedikides, 2002; Judge, et al., 2006), they may avoid interacting with church members one-on-one in any but the most superficial ways. However, those who must work with them daily, such as church staff, are often those who suffer the most from the narcissistic pastor (Patrick, 2010). This can result in a church where attendance increases regularly, but there is a high turnover among pastoral staff; such turnover can result in severe traumatization (Tanner, Wherry, \& Zvonkovic, 2012; Tanner, Zvonkovic, \& Adams, 2012).

Megachurches may fail to address the problems associated with narcissism such as poor ethical judgment (Cooper, et al., 2016) because of the anonymity of the typical worshiper and the celebritylike status of the pastor (Dyer, 2012). Because the church members feel close to the pastor, sitting under his teaching several times per month, their ego needs may be met by this association with a high status leader. The Dominance Complementary Model of narcissistic leadership (Grijalva \& Harms, 2014) predicts that congregations with less dominant members will be more attracted to more dominant leaders in order to ensure that the organization achieves its goals. If it is true that members of larger churches are more passive than members of smaller churches, the tolerance of pastoral narcissism should be greater in larger churches than smaller churches. This could be one factor that explains the tendency to find higher levels narcissism in pastors of megachurches than in pastors of smaller churches. However, talent management theory (Al Ariss, Cascio, \& Paauwe, 2014; Ashton \& Morton, 2005; Chambers, Foulon, Handfield-Jones, Hankin, \& Michaels, 1998) would predict that larger churches have greater resources and thus should be able to hire the most qualified leaders to serve as pastors. This would presumably be limited to pastors who are low in narcissism, given the biblical emphasis on humility in leadership (Mt. 20:25-26, Mk. 10:42-43, I Pet. $5: 3)$. Because most pastors are not high in narcissism (Patrick, 1990), this should be a relatively easy goal to achieve. If talent management theory best describes how churches function, we would expect to see a lower tolerance for pastoral narcissism among members of large churches than in small churches, as the members of large churches would have higher expectations of godliness given their ability to hire the most qualified pastoral talent.

The purpose of this exploratory study is to examine the relationship between tolerance for pastoral narcissism and church size. If the Dominance Complementary Model (Grijalva \& Harms, 2014) best describes the attitudes of church members, we should expect that tolerance of pastoral narcissism should be positively correlated with church size: Larger churches should be more tolerant of pastoral narcissism than smaller churches. If talent management theory best describes how churches choose pastoral leadership, we should expect tolerance for pastoral leadership to be negatively correlated with church size: Larger churches should 
be less tolerant of pastoral narcissism than smaller churches.

As culture undoubtedly plays a role in a church's selection of pastoral leadership, we will also look at aspects of culture that may influence the tolerance of pastoral narcissism. It is possible that individuals from collectivistic and individualistic cultures differ in their tolerance for pastoral narcissism.

With a greater understanding of tolerance of pastoral narcissism, we will be able to develop practical strategies for members of churches, staff members, and denominational leaders who may be in relationship with a narcissistic pastor or who may participate in a search committee that is considering hiring a candidate who may be narcissistic.

\section{Method}

To test the hypothesis that church size predicts tolerance for pastoral narcissism, members of Christian churches in the U.S. were recruited to participate on an online survey. This survey measured the participant's tolerance for pastoral narcissism, the participant's church size, years the participant had attended the church, gender, and age.

\section{Measures}

Tolerance for Narcissism. The Narcissistic Personality Inventory-16 (NPI-16, Ames, Rose, \& Anderson, 2006) is a commonly used measure of a participant's narcissism. The measure has very good psychometric properties. The participants are presented with 16 pairs of statements. Each pair contains one statement that reflects a tendency toward narcissism (e.g., "I really like to be at the center of attention.") and one statement that reflects a tendency toward humility (e.g., "It makes me uncomfortable to be the center of attention."). For each of the 16 pairs, the participants choose the statement which most accurately describes them. The number of narcissistic choices minus the number of humble choices provides a measure of narcissism.

To measure the participants' tolerance for pastoral narcissism, participants were asked to think of the head pastor or leader of their church. Participants were presented the 16 narcissistic statements form the NPI-16 and asked to specify to what degree they felt it was appropriate that their pastor believes each of these statements about himself. Examples include "I think I'm a special person," "I insist upon getting the respect I deserve," and "I like having authority over people." Responses were measured on a Likert-type scale over a range of 1 ("very inappropriate") to 5 ("very appropriate"). Higher total scores for the 16 items indicate a higher tolerance for narcissism. The internal consistency (Cronbach, 1951) of this scale was very good $($ Cronbach's alpha $=.778)$, indicating that the composite score was indeed consistently measuring a single construct.

Expectations for Humility Scale. Similar to the tolerance for narcissism scale, participants indicated the degree that they thought the 16 humility statements from the NPI-16 were appropriate for their pastors to believe about themselves. Examples include "I am no better or no worse than most people," "I usually get the respect I deserve," and "I don't mind following orders." The internal consistency of this scale was poor (Cronbach's alpha $=.494$ ), indicating that the questions did not measure expectations for humility very well. Because of this, the measure was not used for any analysis.

Church Size. Participants subjectively indicated the size of their church on a scale ranging from 1 ("less than 100 people") to 5 (" $1000+$ people").

Culture. Participants were asked in an open-ended question to provide the ethnicity with which they most closely identified. Participants identifying as Asian, Asian-American, Chinese, Chinese-American, Korean, Korean-American, Japanese-American, Hispanic, and Latin were classified as belonging to collectivistic cultures (Singelis, Triandis, Bhawuk, \& Gelfand, 1995). Participants identifying as White or Caucasian were classified as belonging to individualistic cultures. Participants used no other ethnicities to describe themselves.

\section{Participants}

Members of the social network of one of the researchers from Southern California were invited to participate in the online survey if they attended a Christian church in the United States. Of the 64 participants who completed the survey, $71.8 \%$ were female. The length of time they attended their church ranged from 2 months to 38 years, with a mean $(\mathrm{M})=$ 6.71 years, and a standard deviation $(\mathrm{SD})=7.15$ years. Their average age was 36.5 years $(\mathrm{SD}=9.28)$. As for culture, $61.9 \%$ self-identified with a collectivistic culture (56.3\% Asian, 4.7\% Hispanic) and $39.1 \%$ self-identified with an individualistic culture (White or Caucasian). The size of the typical church attended was 201-500 people (on the subjective 1-5 scale, $\mathrm{M}=3.00, \mathrm{SD}=1.55)$. One fifth of the participants $(21.29 \%)$ attended small churches of less than 100 people and almost a third (29.7\%) attended large churches of over 1000 people.

\section{Results}


The purpose of this study was to explore the relationship between tolerance for narcissism and church size. It was hypothesized that the correlation would be positive if the Dominance Complementary Model (Grijalva \& Harms, 2014) best described the attitudes of church members and that it would be negative if talent management theory (Ashton \& Morton, 2005) best described how churches chose leaders. In this sample $(\mathrm{N}=64)$, the correlation between tolerance for narcissism $(\mathrm{M}=2.36, \mathrm{SD}=$ $.48)$ and church size was significantly positive ( $r=$ $.32, p=.0099,2$ tails). This statistical significance means that there is less than a $1 \%$ chance that we could get a correlation this strong (in either direction) by chance in the general population from which our sample was drawn if no such relationship actually existed. Thus, we can be reasonably sure that one's tolerance for pastoral narcissism is positively correlated with one's church size, in accordance with the Dominance Complementary Model.

To test the robustness of this correlation, the relationship was controlled for age, gender, and years attending the church. The model which included all these variables was significant $\left(\mathrm{R}^{2}=.151, p=.044\right)$ and the relationship between tolerance for narcissism and church size continued to be significantly positive ( $\beta=.312, p=.018)$. Thus, the relationship was not due to similarities in age, gender, or length of church attendance. The relationship continued to be positive even when the overlap with these other variables was removed.

The individual items that were most strongly associated with church size were "I think I am a special person" $(r=.38, p=.002)$, "I like having authority over people" $(r=.40, p=.001)$, and especially "I like to be the center of attention" $(r=$ $.65, p<.001)$.

It was also hypothesized that culture may be related to tolerance for narcissism. However, the difference in tolerance for pastoral narcissism between collectivistic cultures $(n=39, M=2.31$, SD $=.46)$ and individualistic cultures $(\mathrm{n}=25, \mathrm{M}=2.43$, $\mathrm{SD}=.50)$ was not significant $(t(62)=1.038, p=.30$, 2 tails). Thus, no conclusions can be drawn about the role of culture and tolerance for narcissism other than that the two groups had very similar scores in this sample.

\section{Discussion}

This exploratory study examined the relationship between tolerance of pastoral narcissism and church size. The results indicate that tolerance for pastoral narcissism is positively correlated with church size. Christians who attend larger churches will tolerate more narcissistic behavior in their pastors than will Christians who attend smaller churches. This corresponds to what would be expected from the Dominance Complementarity Model of narcissistic leadership (Grijalva \& Harms, 2014). Organizations composed of more passive members, who tend to desire to be led, will tolerate greater dominance and narcissism from their leaders than will organizations composed of more active members, who more often seek to participate in the leadership process. Smaller churches tend to have more active members than do larger churches (Dyer, 2012; Paas, 2016) and are thus less tolerant of pastoral narcissism.

\section{Hiring Implications}

Just as larger churches may be more tolerant of narcissistic pastors, narcissistic pastors may seek out large churches as a self-regulatory strategy to maintain and strengthen the narcissistic self (Campbell, et al., 2011). According to the Limelight Model of narcissistic leadership emergence (Nevicka, De Hoogh, Van Vianen, Beersma, \& McIlwain, 2011), leaders high in narcissism seek large stages to show off their competence and superiority. By receiving the adulation of many, their self-image is enhanced and their motivation to perform increases. If there is little public praise for the task at hand, their enthusiasm wains. Thus, their desire to be in the limelight would lead them to seek positions in large churches rather than small ones.

Since narcissists are likely to seek out pastoral positions at large churches, and since they tend to make excellent first impressions (Brunell, et al., 2008; Ong, et al., 2016; Rosenthal \& Pittinsky, 2006), special care must be taken by those responsible for hiring a pastor for a large church. The New Testament standards for leadership place a very high emphasis on humility and serving others, which is incompatible with narcissism and dominance ( $\mathrm{Lk}$ 14:11, I Pt 5:2-3, Mk 10:42-44). Humility (i.e., low narcissism) ought to be one of the requirements for the position. Several strategies can be used to avoid hiring narcissistic pastors. For example, in the pastoral search process, a series of psychological tests can be given that include the NPI (Campbell, et al., 2011; Emmons, 1984; O’Brien, 2017; Raskin \& Hall, 1979). As with all psychological tests, only extremely undesirable scores should be considered in the decision-making process. Similarly, the weight given to any one test should be limited (Hunt, 2007).

A second strategy to avoid hiring a narcissistic pastor focuses on interviews with the candidate. Few candidates would be aware of their own narcissism, and, if they are aware, even fewer would be willing to admit it. Thus, questions posed must indirectly seek information about any past 
narcissistic behavior. Past behavior is often the best predictor of future behavior (Aarts, Verplanken, \& Knippenberg, 1998; Ouellette \& Wood, 1998).This can be done by structuring questions such that responses indicating narcissistic behavior appear to be desired by the interviewer. Examples of such prompts include "Describe a time when you needed to get angry to get something done," "Give an example of when you got away with something that most other people would not have been able to do," and "How have you responded to subordinates who have questioned your authority?" Responses in any interview will reflect a self-enhancing spin regardless of who is being interviewed. However, any sign of narcissism in response to these types of questions should be a red flag and considered in the hiring process.

A third strategy involves interviewing people that have worked either above or below the candidate. Because narcissists tend to work together and appreciate each other's dominating leadership style (Burton et al., 2017; Hart \& Adams, 2014; Maaß, Lämmle, Bensch, \& Ziegler, 2016), the references provided by a narcissistic candidate are unlikely to provide any useful information about the candidate's moral character. A better strategy is to find other people who know the candidate well, including people that have worked both above and below the candidate. Apart from other narcissists, people who know a narcissist well tend to view him as a poor leader (Judge, et al., 2006). They likely have observed the narcissist's lack of empathy and tendency to damage relationships by undermining other people's goals in order to promote his own. These traits are not visible during an interview because the candidate's extraversion, charm, and vision dominate a hiring committee's first impressions. Former supervisors can provide useful information about a candidate's ability to work with others, his ability to receive performance feedback, his level of empathy, his ability to handle concerns and criticism voiced to him, his ability to submit to authority, and his integrity (Blair, Hoffman, \& Helland, 2008). Former employees who have worked under a candidate can especially provide good information about how the candidate treats people under his authority, those who will be the prime target of any abuses of power (Dunaetz, 2016; Kipnis, 1976, 1984). Both former supervisors and subordinates should be asked specific questions to uncover a detailed picture of the candidate's personality, especially the candidate's level of humility and willingness to serve others.

\section{Beyond Chocolate Cake: Life with the Narcissistic Pastor}

In the Chocolate Cake Model of narcissistic leadership (Campbell, et al., 2011), life with the narcissistic leader begins well but finishes poorly. During the period of leadership emergence, the narcissist's strengths are clear but his motives are not, often leading followers to view him as a transformational leader (Judge, et al., 2006). However, once his motives become clear and his behavior becomes less and less ethical, many followers find his leadership unacceptable (Campbell, et al., 2011; Judge, Bono, Ilies, \& Gerhardt, 2002). The recently developed Energy Clash Model of narcissistic leadership (Sedikides \& Campbell, 2017) goes a step further than the Chocolate Cade Model to include how narcissistic leadership affects an organization in the long term. In the Energy Clash Model, the narcissistic leader is viewed as a powerful source of energy that enters a system with vision and excitement, throwing the system out of its long-established equilibrium, for good or for bad. After this initial perturbation, comes a period of conflict. Forces that appreciated the status quo resist the changes. Forces that perceive the changes to be ethically or personally unacceptable push back to prevent the actions of the narcissist from creating unacceptable consequences. During this time, the narcissistic leader strives to enact his vision. The system responds to these changes with the resolution, which typically involves either the narcissistic leader leaving or the rest of the organization adapting to the changes, which may imply that some or many members leave the organization (Sedikides \& Campbell, 2017). One of the immediate implications of the Energy Clash Model (Sedikides \& Campbell, 2017) is that pastoral staff members who are forced to resign, who are fired, or who are abused in some other way by a narcissistic pastor (Patrick, 2010) can take comfort from the fact that their dismissal may have resulted from their intolerance of ungodly behavior (2 Tim 3:12). The involuntary termination of pastoral staff can be extremely distressing (Tanner, Wherry, et al., 2012; Tanner, Zvonkovic, et al., 2012). However, when involuntary termination is due to resisting an ungodly leader it can be worn as a badge of honor rather than shame.

However, for both pastoral staff and church members who find themselves under a narcissistic pastor, resignation is not the only strategy that can be used. Although narcissism is often described as an unchanging personality trait, it can, in fact, vary from situation to situation (Giacomin \& Jordan, 2014; Konrath, O'Brien, \& Hsing, 2006; Li et al., 2015; Ronningstam \& Gunderson, 1996; Ronningstam, Gunderson, \& Lyons, 1995; Sakellaropoulo \& Baldwin, 2007). For example, Li et al. (2015) 
temporarily increased the narcissism and aggressiveness of the participants in an experiment by having them imagine themselves as being "beautiful, charming, vigorous, unique, and omnipotent" (p. 13, a message not unlike some heard in large churches) and to imagine "the world exists for you and because of you" (p. 13). Giacomin and Jordan (2014) demonstrated that inducing feelings of empathy and interdependence can reduce narcissism in those experiencing such feelings. Konrath et al. (2006) found that narcissists could be made less aggressive toward a partner if they were told that they had something in common with their partner, such as a birthdate. Even being told that they had something in common with a partner as trivial as a "fingerprint type" caused them to be less aggressive.

For those in close proximity to a narcissistic pastor, these phenomena can be used to help minimize the likelihood of destructive behaviors. Most pastors with a tendency towards narcissism would probably prefer being humble, given a choice. Those who work closely with them can encourage the behavior associated with humility (in contrast to the behavior associated with narcissism) by making general comments about the importance of service (Li, et al., 2015), the sinfulness and need for a savior that characterize all of humanity (even leaders), and the importance of interdependence in serving the Lord (Giacomin \& Jordan, 2014). Dominating, dangerous behavior can also be reduced by emphasizing various commonalities shared with the leader (Konrath, et al., 2006). However, these strategies may have limited effectiveness in extreme cases of pastoral narcissism.

\section{Encouraging Godly Behavior through Accountability}

Although the Dominance Complementarity Model of narcissistic leadership (Grijalva \& Harms, 2014) predicts that less dominant groups of individuals will more likely appreciate narcissistic leaders and that narcissistic leaders will best perform with a passive audience that gives them the recognition that they desire, such a situation in a church does not remove the need for pastoral accountability. Narcissists who are accountable for their behavior are less likely to engage in willful and harmful behaviors such as publically humiliating or verbally attacking their subordinates, behaviors commonly associated with narcissism. A board or a mentor who carefully monitors a narcissistic pastor, calling attention to specific destructive behaviors, can provide the motivation necessary to encourage more godly behavior.

However, narcissists tend to prefer to work with others who have personality traits (including narcissism) and ethical values that are similar to their own (Burton, et al., 2017; Hart \& Adams, 2014; Maaß, et al., 2016). Although narcissists appreciate more passive and less dominant followers, they often surround themselves with ambitious individuals who are willing to flatter and admire them in order to get ahead (Ouimet, 2010). This presents a special problem for growing churches. As churches grow, their structure needs to evolve. Narcissistic pastors may be tempted to restructure the system of accountability, creating a board that is filled with people that will support them in virtually any situation rather than hold them accountable for their specific behaviors. For example, a megachurch pastor might make himself accountable to a board consisting only of other megachurch pastors (Funk \& Rothacker, 2016; Menzie, 2013). To prevent a growing church from coming under the control of a narcissistic pastor who will create his own accountability structure that does little or nothing to limit the destructive behaviors associated with narcissism, current board members must be aware of the dangers that would come from such a change in structure. Such topics should be discussed with potential pastoral candidates in order to avoid power struggles before they occur.

In some situations (but certainly not all), more creative forms of accountability might be appropriate. One form of accountability that can build upon a narcissistic pastor's need for approval and recognition comes from linking the church's reputation to the pastor's reputation. If the two are intricately linked, the pastor will be more motivated to avoid behaviors that damage the church (Grijalva \& Harms, 2014). They can be linked through the web site and other publicity materials. Rather than hiding the leadership from the public (as some church publicity material does), a church can make the pastor its "main face" or the personification of its brand. Such a close identification can motivate a narcissistic pastor to work for the church rather than against it by making the pastor's well-being dependent on the church's well-being. Another creative and less direct way of linking a pastor to a church and holding him accountable is through anonymous blogs. Narcissists typically monitor their web presence carefully. An anonymous blog which describes the pastor's behavior, praising it when it is God honoring and questioning it when it is not, can motivate a pastor to act in a God honoring way, especially if he knows other people are reading it. Writing such a blog, of course, is risky for staff members; narcissists have little tolerance for those who question their behavior.

\section{Conclusion}


This study has demonstrated that church members' tolerance for pastoral narcissism is greater in larger churches than in smaller churches. This may be a contributing factor to the perception that pastors of megachurches tend to be more narcissistic than pastors of smaller churches. Although narcissistic pastors are initially attractive to churches which need change, such pastors can cause much pain, especially to those who must work closely alongside them. The potential damage can be attenuated through awareness of the dangers associated with narcissism and by maintaining accountability structures that encourage godly behaviors.

Although, as sinners in need of redemption, we all might have tendencies toward narcissism, with the help and support of others and by God's grace, these tendencies can be checked, in spite of the frustrations that such accountability might entail.

\section{References}

Aarts, H., Verplanken, B., \& Knippenberg, A. (1998). Predicting behavior from actions in the past: Repeated decision making or a matter of habit? Journal of Applied Social Psychology, 28, 13551374.

Al Ariss, A., Cascio, W. F., \& Paauwe, J. (2014). Talent management: Current theories and future research directions. Journal of World Business, 49, 173-179.

American Psychiatric Association. (2013). Diagnostic and statistical manual of mental disorders (5th ed.). Arlington, VA: American Psychiatric Publishing.

Ames, D. R., Rose, P., \& Anderson, C. P. (2006). The NPI16 as a short measure of narcissism. Journal of Research in Personality, 40, 440-450.

Ashton, C., \& Morton, L. (2005). Managing talent for competitive advantage: Taking a systemic approach to talent management. Strategic $H R$ Review, 4, 28-31.

Blair, C. A., Hoffman, B. J., \& Helland, K. R. (2008). Narcissism in organizations: A multisource appraisal reflects different perspectives. Human Performance, 21, 254-276.

Brown, R. P., \& Zeigler-Hill, V. (2004). Narcissism and the non-equivalence of self-esteem measures: A matter of dominance? Journal of Research in Personality, 38, 585-592.

Brunell, A. B., Gentry, W. A., Campbell, W. K., Hoffman, B. J., Kuhnert, K. W., \& DeMarree, K. G. (2008). Leader emergence: The case of the narcissistic leader. Personality and Social Psychology Bulletin, 34, 1663-1676.

Burton, K. A., Adams, J. M., Hart, W., Grant, B., Richardson, K., \& Tortoriello, G. (2017). You remind me of someone awesome: Narcissistic tolerance is driven by perceived similarity. Personality and Individual Differences, 104, 499503.
Bushman, B. J., Bonacci, A. M., Van Dijk, M., \& Baumeister, R. F. (2003). Narcissism, sexual refusal, and aggression: Testing a narcissistic reactance model of sexual coercion. Journal of Personality and Social Psychology, 84, 10271040.

Campbell, W. K., Brunell, A. B., \& Finkel, E. J. (2006). Narcissism, interpersonal self-regulation, and romantic relationships: An agency model approach. In E. J. Finkel \& K. D. Vohs (Eds.), Self and relationships: Connecting intrapersonal and interpersonal processes (pp. 57-83). New York, NY: Guiliford.

Campbell, W. K., Goodie, A. S., \& Foster, J. D. (2004). Narcissism, confidence, and risk attitude. Journal of Behavioral Decision Making, 17, 297-311.

Campbell, W. K., Hoffman, B. J., Campbell, S. M., \& Marchisio, G. (2011). Narcissism in organizational contexts. Human Resource Management Review, 21, 268-284.

Campbell, W. K., Rudich, E. A., \& Sedikides, C. (2002). Narcissism, self-esteem, and the positivity of self-views: Two portraits of self-love. Personality and Social Psychology Bulletin, 28, 358-368.

Chambers, E. G., Foulon, M., Handfield-Jones, H., Hankin, S. M., \& Michaels, E. G. (1998). The war for talent. The McKinsey Quarterly, 1998(3), 44-51.

Cooper, M. J., Pullig, C., \& Dickens, C. (2016). Effects of narcissism and religiosity on church ministers with respect to ethical judgment, confidence, and forgiveness. Journal of Psychology \& Theology, $44,42-54$.

Cronbach, L. J. (1951). Coefficient alpha and the internal structure of tests. Psychometrika, 16, 297-334.

Dunaetz, D. R. (2016). Submission or cooperation? Two competing approaches to conflict management in mission organizations. In R. Cathcart Scheuermann \& E. L. Smither (Eds.), Controversies in mission: Theology, people, and practice in the 21st century (pp. 121-142). Pasadena, CA: William Carey Library.

Dyer, J. E. (2012). Loving thyself: A Kohutian interpretation of a "limited" mature narcissism in evangelical megachurches. Journal of religion and health, 51, 241-255.

Emmons, R. A. (1984). Factor analysis and construct validity of the Narcissistic Personality Inventory. Journal of Personality Assessment, 48, 291-300.

Foster, J. D., Shrira, I., \& Campbell, W. K. (2006). Theoretical models of narcissism, sexuality, and relationship commitment. Journal of Social and Personal Relationships, 23, 367-386.

Funk, T., \& Rothacker, R. (2016, July 12). Elevation Church stands out in Charlotte for its growth and governance, Charlotte Observer. Retrieved from http://www.charlotteobserver.com/living/religion/ article89164002.html

Giacomin, M., \& Jordan, C. H. (2014). Down-regulating narcissistic tendencies: Communal focus reduces state narcissism. Personality and Social Psychology Bulletin, 40, 488-500. 
Grijalva, E., \& Harms, P. D. (2014). Narcissism: An integrative synthesis and dominance complementarity model. The Academy of Management Perspectives, 28, 108-127.

Grijalva, E., Newman, D. A., Tay, L., Donnellan, M. B., Harms, P. D., Robins, R. W., \& Yan, T. (2015). Gender differences in narcissism: A metaanalytic review. Psychological Bulletin, 141, 261.

Hart, W., \& Adams, J. M. (2014). Are narcissists more accepting of others' narcissistic traits? Personality and Individual Differences, 64, 163167.

Higgs, M. (2009). The good, the bad and the ugly: Leadership and narcissism. Journal of Change Management, 9, 165-178.

Hunt, S. (2007). Hiring success: The art and science of staffing assessment and employee selection. San Francisco, CA: Pfeiffer.

Judge, T. A., Bono, J. E., Ilies, R., \& Gerhardt, M. W. (2002). Personality and leadership: A qualitative and quantitative review. Journal of Applied Psychology, 87, 765-780.

Judge, T. A., LePine, J. A., \& Rich, B. L. (2006). Loving yourself abundantly: Relationship of the narcissistic personality to self- and other perceptions of workplace deviance, leadership, and task and contextual performance. Journal of Applied Psychology, 91, 762-775.

Kipnis, D. (1976). The powerholders. Chicago, IL: University of Chicago Press

Kipnis, D. (1984). The use of power in organizations and in interpersonal settings. Applied Social Psychology Annual, 5, 179-210.

Konrath, S. H., O'Brien, E. H., \& Hsing, C. (2006). Changes in dispositional empathy in American college students over time: A meta-analysis. Personality and Social Psychology Review, 15, 180-198.

Lee, K., \& Ashton, M. C. (2005). Psychopathy, Machiavellianism, and narcissism in the fivefactor model and the HEXACO model of personality structure. Personality and Individual Differences, 38, 1571-1582.

Li, C., Sun, Y., Ho, M. Y., You, J., Shaver, P. R., \& Wang, Z. (2015). State narcissism and aggression: The mediating roles of anger and hostile attributional bias. Aggressive Behavior, 2015, 1-13.

Maaß, U., Lämmle, L., Bensch, D., \& Ziegler, M. (2016). Narcissists of a feather flock together: Narcissism and the similarity of friends. Personality and Social Psychology Bulletin, 42, 366-384.

Maccoby, M. (2000). Narcissistic leaders: The incredible pros, the inevitable cons. Harvard Business Review, 78, 68-78.

Meloy, J. R. (1986). Narcissistic psychopathology and the clergy. Pastoral Psychology, 35, 50-55.

Menzie, N. (2013, Oct 30). Who are the megachurch leaders who decide Elevation Church pastor Steven Furtick's 'secret' salary and influence his ministry?, The Christian Post. Retrieved from http://www.christianpost.com/news/who-are-themegachurch-leaders-who-decide-elevation- church-pastor-steven-furticks-secret-salary-andinfluence-his-ministry-107741/

Nevicka, B., De Hoogh, A. H. B., Van Vianen, A. E. M., Beersma, B., \& Mcllwain, D. (2011). All I need is a stage to shine: Narcissists' leader emergence and performance. The Leadership Quarterly, 22, 910-925.

O'Brien, C. (2017). Can pre-employment tests identify white-collar criminals and reduce fraud risk in your organization? Journal of Forensic and Investigative Accounting, 9, 621-636.

Ong, C. W., Roberts, R., Arthur, C. A., Woodman, T., \& Akehurst, S. (2016). The leader ship is sinking: A temporal investigation of narcissistic leadership. Journal of Personality, 84, 237-247.

Ouellette, J. A., \& Wood, W. (1998). Habit and intention in everyday life: The multiple processes by which past behavior predicts future behavior. Psychological Bulletin, 124, 54-74.

Ouimet, G. (2010). Dynamics of narcissistic leadership in organizations: Towards an integrated research model. Journal of Managerial Psychology, 25, 713-726.

Paas, S. (2016). Church planting in the secular west: Learning from the European experience. Grand Rapids, MI: William B. Eerdmans Publishing.

Patrick, J. (1990). Assessment of narcissistic psychopathology in the clergy. Pastoral Psychology, 38, 173-180.

Patrick, J. (2010, November). Working with a narcissistic leader. Retrieved from http://www.christianitytoday.com/pastors/2010/n ovember-onlineonly/workingnarcissisticleader.html

Paulhus, D. L., Harms, P. D., Bruce, M. N., \& Lysy, D. C. (2003). The over-claiming technique: Measuring self-enhancement independent of ability. Journal of Personality and Social Psychology, 84, 890904.

Raskin, R. N., \& Hall, C. S. (1979). A narcissistic personality inventory. Psychological Reports, 45, 590.

Raskin, R. N., Novacek, J., \& Hogan, R. (1991). Narcissistic self-esteem management. Journal of Personality and Social Psychology, 60, 911-918.

Ronningstam, E., \& Gunderson, J. (1996). Narcissistic personality - a stable disorder or a state of mind. Psychiatric Times, 13, 35-36.

Ronningstam, E., Gunderson, J., \& Lyons, M. (1995). Changes in pathological narcissism. American Journal of Psychiatry, 152, 253-257.

Rosenthal, S. A., \& Pittinsky, T. L. (2006). Narcissistic leadership. The Leadership Quarterly, 17, 617633.

Sakellaropoulo, M., \& Baldwin, M. W. (2007). The hidden sides of self-esteem: Two dimensions of implicit self-esteem and their relation to narcissistic reactions. Journal of Experimental Social Psychology, 43, 995-1001.

Sedikides, C., \& Campbell, W. K. (2017). Narcissistic force meets systemic resistance: The energy clash 
model. Perspectives on Psychological Science, $12,400-421$.

Singelis, T. M., Triandis, H. C., Bhawuk, D. P. S., \& Gelfand, M. J. (1995). Horizontal and vertical dimensions of individualism and collectivism: A theoretical and measurement refinement. CrossCultural Research, 29, 240-275.

Tanner, M. N., Wherry, J. N., \& Zvonkovic, A. M. (2012). Clergy who experience trauma as a result of forced termination. Journal of Religion and Health, 1-15. doi: doi:10.1007/s10943-012-95713.

Tanner, M. N., Zvonkovic, A. M., \& Adams, C. (2012). Forced termination of American clergy: Its effects and connection to negative well-being. Review of Religious Research, 54, 1-17.

Twenge, J. M., \& Campbell, W. K. (2009). The narcissism epidemic: Living in the age of entitlement. New York, NY: Simon and Schuster.

Twenge, J. M., Konrath, S., Foster, J. D., Campbell, W. K., \& Bushman, B. J. (2008). Egos inflating over time: A cross-temporal meta-analysis of the Narcissistic Personality Inventory. Journal of Personality, 76, 875-902.

Zondag, H. J. (2004). Just like other people: Narcissism among pastors. Pastoral Psychology, 52, 423437.

\section{About the Authors}

David R. Dunaetz (Ph.D., Claremont Graduate University) is an assistant professor of organizational psychology at Azusa Pacific University, CA. His research program focuses on conflict processes in Christian organizations.ddunaetz@apu.edu

Hannah L. Jung (M.S., Azusa Pacific University) is an adjunct professor of leadership at Azusa Pacific University. Her passion is leadership development and helping churches function more effectively. hjung@apu.edu

Stephen L. Lambert (Psy.D., California School of Professional Psychology) is an associate professor of psychology at Azusa Pacific University. His speciality is linking pastoral theology and and psychological theory.slambert@apu.edu 